TUGAS PEMOGRAMAN 1 RUMAH SAKIT

$\begin{array}{ll}\text { NPM } & : \mathbf{1 9 4 2 1 0 3 3} \\ \text { NAMA } & \text { : IYON RIFALDO } \\ \text { PRODI } & : \text { INFORMATIKA } \\ \text { FAKULTAS } & : \text { ILMU KOMPUTER } \\ \text { EMAIL } & : \text { rifaldoiyOn69@gmail.com }\end{array}$

SOAL TUGAS :

1. Buatlah Program dengan ketentuan sebagai berikut : Input :

kode pasien $=$ PS0003

Kode Kamar $=\mathbf{4 4 4 4 4}$

Lama Menginap $=5$ hari

Kode Dokter $=$ DK003

\begin{tabular}{|l|l|l|}
\hline Kode Pasien & Status Pasien & Biaya Daftar Pasien \\
\hline PS0001 & Pasien Baru & Rp. 500.000 \\
\hline PS0002 & Pasien Lama & Rp. 400.000 \\
\hline PS0003 & Pasien BPJS & Rp. 300.000 \\
\hline PS0004 & Pasien Askes & Rp. 200.000 \\
\hline
\end{tabular}

\begin{tabular}{|l|l|l|}
\hline Kode Kamar & Nama Kamar & Biaya Kamar \\
\hline 1111 & Kamar Melati & Rp. 1.000 .000 \\
\hline 2222 & Kamar Mawar & Rp. 2.000 .000 \\
\hline 3333 & Kamar Dahlia & Rp. 3.000 .000 \\
\hline 4444 & Kamar Anggrek & Rp. 4.000 .000 \\
\hline 5555 & Kamar Tulip & Rp. 5.000 .000 \\
\hline
\end{tabular}

\begin{tabular}{|l|l|l|}
\hline Kode Dokter & Nama Dokter & Biaya Pemeriksaan \\
\hline DK001 & DR. Andi & Rp. 500.000 \\
\hline DK002 & DR. Joko & Rp. 400.000 \\
\hline DK003 & DR. Karni & Rp. 300.000 \\
\hline DK004 & DR. Amin & Rp. 200.000 \\
\hline DK005 & DR. Udin & Rp. 100.000 \\
\hline
\end{tabular}

\begin{tabular}{|l|l|}
\hline Lama Menginap & Diskon \\
\hline$>10$ Hari & $50 \%$ dari Biaya Kamar \\
\hline$>8$ Hari & $40 \%$ dari Biaya Kamar \\
\hline$>6$ Hari & $30 \%$ dari Biaya Kamar \\
\hline$>4$ Hari & $20 \%$ dari Biaya Kamar \\
\hline$>+1$ & $10 \%$ dari Biaya Kamar \\
\hline
\end{tabular}

Total Bayar = Biaya Daftar Pasien + Biaya Kamar + Biaya Pemeriksaan - Diskon

Output (Tampilkan) $=$

Status Pasien

Biaya daftar Pasien 


\section{Nama Kamar}

Biaya Kamar

Nama Dokter

Biaya Pemeriksaan

Diskon

Total Bayar

\section{SOURCE CODE / KODING PROGRAM (KETIK DIBAWAH INI)}

public class RumahSakitPutiMinang\{

public static void main(String[] args)\{

String kodepasien = "PSO003";

double kodekamar $=4444$;

double lamamenginap = 5;

String kodedokter = "DK003";

String statuspasien;

double biayadaftar;

String namakamar;

double biayakamar;

String namadokter;

double biayapemeriksaan;

double diskon;

double total;

if (kodepasien==("PS0001"))\{statuspasien = "Pasien Baru"; biayadaftar = 500000;

\}else if (kodepasien==("PS0002"))\{statuspasien = "Pasien Lama"; biayadaftar = 400000;

\}else if $($ kodepasien==("PS0003")) \{statuspasien = "Pasien BPJS"; biayadaftar = 300000;

\}else $\{$ kodepasien="PS0004"; statuspasien = "Pasien Askes"; biayadaftar = 200000;

if $($ kodekamar==(1111) $\{$ namakamar = "Kamar Melati"; biayakamar = 1000000;

\}else if $($ kodekamar==(2222)) \{namakamar = "Kamar Mawar"; biayakamar = 2000000;

\}else if $($ kodekamar==(3333))\{namakamar = "Kamar Dahlia"; biayakamar = 3000000;

\}else if $($ kodekamar==(4444))\{namakamar = "Kamar Anggrek"; biayakamar = 4000000;

\}else $\{$ kodekamar=5555; namakamar = "Kamar Tulip"; biayakamar $=5000000 ;\}$

if (kodedokter==("DK001"))\{namadokter = "DR. Andi"; biayapemeriksaan = 500000;

\}else if (kodedokter==("DK002"))\{namadokter = "DR. Joko"; biayapemeriksaan = 400000;

\}else if (kodedokter==("DK003"))\{namadokter = "DR. Karni"; biayapemeriksaan = 300000;

\}else if (kodedokter==("DK004"))\{namadokter = "DR. Amin"; biayapemeriksaan = 200000;

\}else \{kodedokter="DK004"; namadokter = "DR. Udin"; biayapemeriksaan = 100000; 
If (lamamenginap>=10)\{diskon=biayakamar *50/100;\}

else if (lamamenginap>=8)\{diskon=biayakamar *40/100;\}

else if (lamamenginap>=6)\{diskon=biayakamar *30/100;\}

else if (lamamenginap>=4)\{diskon=biayakamar *20/100;\}

else if (lamamenginap>=1)\{diskon=biayakamar *10/100;\}

else $\{$ diskon $=0 ;\}$

total = biayadaftar+biayakamar+biayapemeriksaan-diskon;

System.out.println("Status Pasien = "+statuspasien);

System.out.printIn("Biaya Daftar Pasien = "+biayadaftar);

System.out.printIn("Nama Kamar = "+namakamar);

System.out.printIn("Biaya Kamar = "+biayakamar);

System.out.printIn("Nama Dokter = "+namadokter);

System.out. printIn("Biaya Pemeriksaan = "+biayapemeriksaan);

System.out.println("Diskon = "+diskon);

System.out.printIn("Total Bayar = "+total); 


\section{PENJELASAN SOURCE CODE (KETIK DIBAWAH INI)}

Public class digunakan untuk menyatakan bahwa kelas tersebut dapat diakses kelas lain manapun.

String digunakan untuk tipe data huruf, angka, spasi, dan berbagai karakter.

Int digunakan untuk tipe data angka yang tidak menggunakan koma.

Double digunakan tipe data untuk angka, sama seperti int, tapi double dapat menggunakan koma.

String kodepasien = kode pasien menggunakan tipe data string double kodekamar = kode kamar menggunakan tipe data double double lamamenginap = lama menginap menggunakan tipe data double String kodedokter $=$ kode dokter menggunakan tipe data string String statuspasien = status pasien menggunakan tipe data string double biayadaftar = biaya daftar menggunakan tipe data double String namakamar = nama kamar menggunakan tipe data string double biayakamar = biaya kamar menggunakan tipe data double String namadokter = nama dokter menggunakan tipe data string double biayapemeriksaan = biaya pemeriksaan menggunakan tipe data double double diskon = diskon menggunakan tipe data double double total = total bayar menggunakan tipe data double

If Else digunakan untuk pengujian sebuah kondisi. Jika kondisi yang di uji tersebut terpenuhi, maka program akan menjalankan pernyataan-peryataan tertentu.

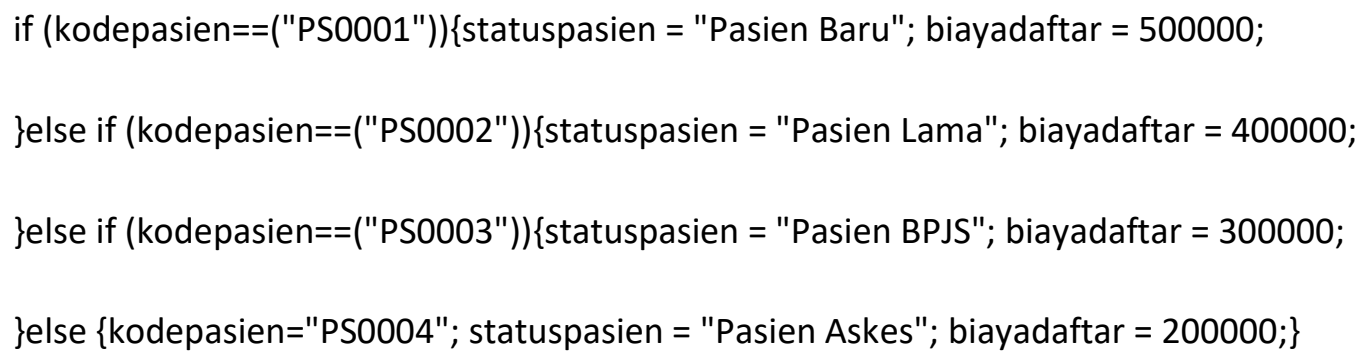

Pernyataan if mempunyai pengertian, "jika kondisi bernilai benar, maka perintah -1 akan dikerjakan dan jika tidak memenuhi syarat maka akan mengerjakan perintah -2 dan seterusnya.

if $($ kodekamar==(1111)) \{namakamar = "Kamar Melati"; biayakamar = 1000000;

\}else if (kodekamar==(2222))\{namakamar = "Kamar Mawar"; biayakamar = 2000000;

\}else if (kodekamar==(3333))\{namakamar = "Kamar Dahlia"; biayakamar = 3000000;

\}else if $($ kodekamar==(4444))\{namakamar = "Kamar Anggrek"; biayakamar = 4000000;

\}else $\{$ kodekamar=5555; namakamar $=$ "Kamar Tulip"; biayakamar $=5000000 ;\}$

Pernyataan if mempunyai pengertian, "jika kondisi bernilai benar, maka perintah -1 akan dikerjakan dan jika tidak memenuhi syarat maka akan mengerjakan perintah -2 dan seterusnya. 
\}else if (kodedokter==("DK002"))\{namadokter = "DR. Joko"; biayapemeriksaan = 400000;

\}else if (kodedokter==("DK003"))\{namadokter = "DR. Karni"; biayapemeriksaan = 300000;

\}else if (kodedokter==("DK004"))\{namadokter = "DR. Amin"; biayapemeriksaan = 200000;

\}else \{kodedokter="DK004"; namadokter = "DR. Udin"; biayapemeriksaan = 100000;

Pernyataan if mempunyai pengertian, "jika kondisi bernilai benar, maka perintah -1 akan dikerjakan dan jika tidak memenuhi syarat maka akan mengerjakan perintah $\mathbf{- 2}$ dan seterusnya.

if (lamamenginap $>=10)\{$ diskon=biayakamar $* 50 / 100 ;\}$

else if (lamamenginap $>=8)\{$ diskon=biayakamar *40 /100;

else if (lamamenginap>=6)\{diskon=biayakamar *30/100;\}

else if (lamamenginap>=4)\{diskon=biayakamar *20/100;

else if (lamamenginap>=1)\{diskon=biayakamar *10 /100;

else $\{$ diskon $=0 ;\}$

(keterangan total dihasilkan dari biaya daftar pasien ditambah biaya kamar ditambah biaya pemeriksaan dan dikurangi diskon sesuai ketentuan yang berlaku)

total = biayadaftar+biayakamar+biayapemeriksaan-diskon;

(untuk mengeluarkan hasil pengodean)

System.out. println("Status Pasien = "+statuspasien); System.out. printIn("Biaya Daftar Pasien = "+biayadaftar); System.out.printIn("Nama Kamar = "+namakamar); System.out.printIn("Biaya Kamar = "+biayakamar); System.out.printIn("Nama Dokter = "+namadokter); System.out.printIn("Biaya Pemeriksaan = "+biayapemeriksaan); System.out.print In("Diskon = "+diskon); System.out.printIn("Total Bayar = "+total); 


\section{FLOWCHART PROGRAM}

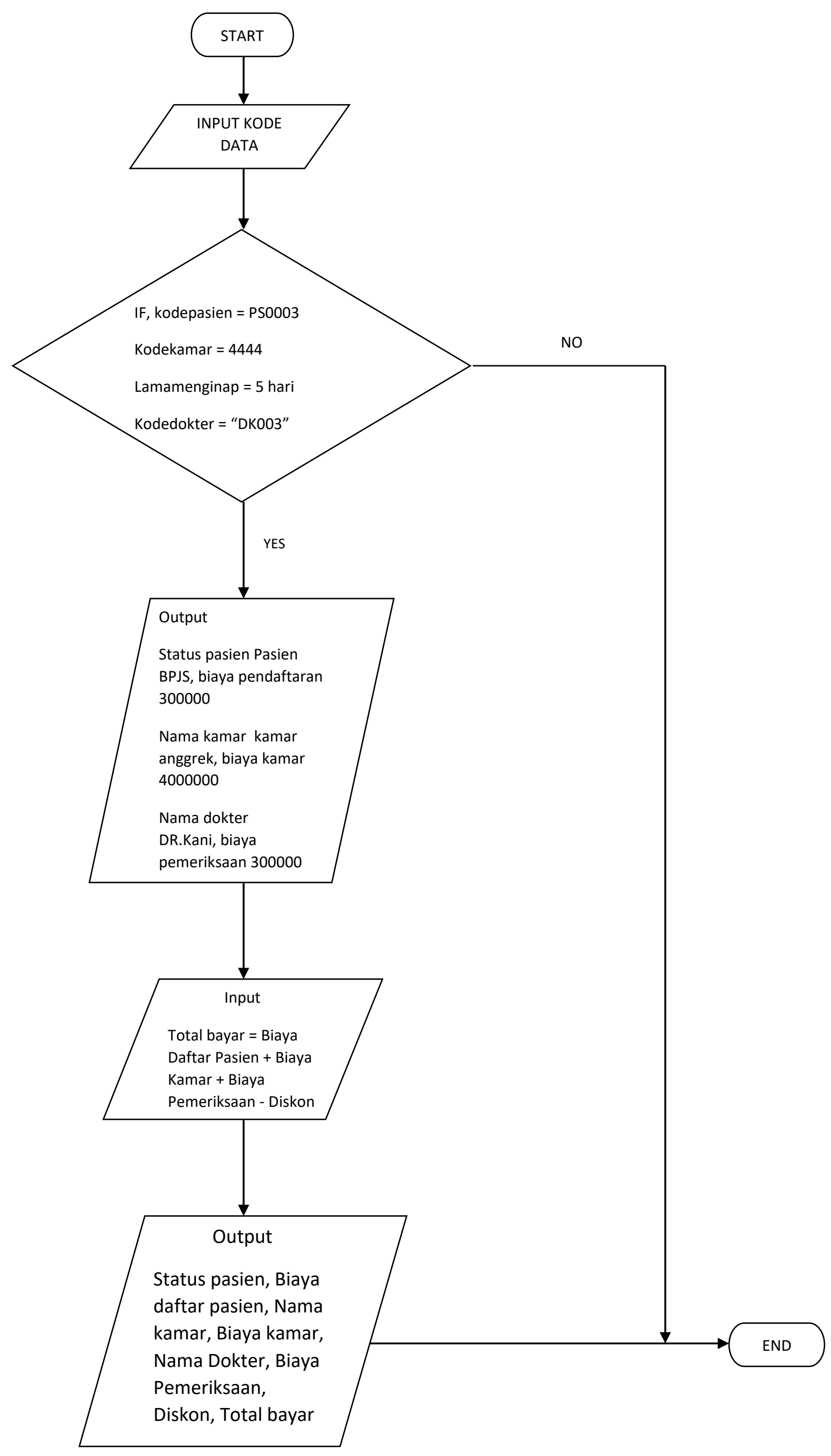




\section{REFERENSI :}

Endra, R. Y. (2019, October 29). Belajar Mudah Algoritma dan Pemograman Java. Retrieved from osf.io/v7yfn

Endra, R. Y. (2019, October 29). Internet of Things. Retrieved from osf.io/4h8sf 